\title{
TURNOVER INTENTION DITINJAU DARI KOMITMEN, KEPUASAN KERJA DAN KEUNGGULAN BERSAING (Studi Kasus Pada Karyawan PT. Solo Murni)
}

\author{
Ferdian Ramadhan Putra ${ }^{1}$, Istiatin ${ }^{2}$, Djumali $^{3}$ \\ Islam Batik University of Surakarta \\ Email :ferdian4550@gmail.com
}

\begin{abstract}
In addition to reducing the need for workers from other companies, PT also reduces the number of employees. Pure Solo for Boyolali. The aims of this study is to determine the interaction between interactions, To analyze the competitive advantage of job satisfaction and competition goals of PT. Pure Solo for Boyolali. Testing methods include quantitative representation; The sampling technique used in the cluster sample and the Slowan formula provides a sample of 97 employees from the production department. Data analysis techniques used various linear regressions; F test; $t$ test coefficient. The results shown are: 1) Commitment; Job satisfaction and competitive advantage significantly affect the motives and intentions of employees to change PT. Solo Murni, Boyolali, 2) encouraged PT staff to be positive and part of the competition. Purely solo in Boyolali; 3) Job satisfaction has a positive and partial effect on employee motivation to replace PT. According to Boyolali's four competitive advantages, Murni Murni has a positive and partial impact on PT. Staff competition. Pure Solo for Boyolali.
\end{abstract}

Keywords: turnover intention, comitment, job satisfaction, competitive advantage

\section{PENDAHULUAN}

Seiring dengan perkembangan jumlah penduduk Indonesia yang semakin meningkat dan perkembangan dunia industri, perlu meningkatkan tingkat keberhasilan angkatan kerja yang mampu memenuhi sektor industri tersebut. Kuncinya adalah tenaga kerja, yang dapat bersaing di dunia industri, di mana mereka memainkan peran penting dalam menjalankan kegiatan bisnis perusahaan untuk mencapai tujuannya.

Keberadaan karyawan yang berkualitas dan diikuti oleh suatu bisnis dapat menciptakan dan mempertahankan kinerja bisnis yang efektif. Jika sejumlah besar karyawan tidak berkualitas baik, sulit bagi perusahaan untuk bersaing dengan perusahaan lain. Hal ini dapat berdampak buruk bagi perusahaan dan menyebabkan karyawan memiliki niat rotasi yang menghasilkan keputusan untuk meninggalkan perusahaan. Niat bisnis dapat mengakibatkan hilangnya bakat manusia dan aset yang berharga yang akan mengakibatkan kerugian bagi bisnis (Paripurna, Supartha \& Subudi, 2017). Tingginya tingkat niat untuk mentransfer ke domain dalam perusahaan menunjukkan bahwa domain tersebut harus diperbaiki dalam hal kondisi kerja dan pelatihan karyawannya (Melky, 2015). Hal ini dapat menimbulkan pengaruh yang buruk terhadap kegiatan perusahaan. Karena itu, perusahaan harus selalu memperhatikan banyak faktor yang dapat memengaruhi niat untuk beralih ke pendapatan melalui keterlibatan, kepuasan kerja karyawan, dan keunggulan kompetitif.. 
Komitmen menunjukkan keperca-yaan pada kemampuan mereka untuk menerima tujuan organisasi dan ingin terus menjadi bagian dari organisasi (Soekiyono, 2017). Karyawan yang mengaitkannya tinggi setia kepada perusahaan yang akan selalu berpartisipasi dalam semua kegiatan untuk kebaikan perusahaan. Karyawan yang jujur adalah aset bisnis paling penting dalam mencapai tujuan bisnis. Kondisi ini dapat dipenuhi jika perusahaan dapat memenuhi kepuasan kerja. Adapun kepuasan kerja, perusahaan menawarkan manfaat dengan meningkat-kan produksi, meningkatkan sikap dan perilaku karyawan (Hafni dan Lyana, 2016). Karyawan pada kepuasan kerja yang tinggi memiliki emosi positif, sedangkan mereka yang memiliki kepuasan kerja yang rendah memiliki emosi negatif tentang pekerjaan mereka (Paripurna, Supartha \& Subudi, 2017).

Sebagai sumber daya kerja, karyawan pada perusahaan perlu untuk dilatih dengan baik, guna mencapai keunggulan bersaing (competitive advantage) perusahaan, agar memiliki daya saing dan mampu untuk bersaing dengan industri lain. Karyawan yang unik dan memiliki nilai pembeda sangat menunjang keunggulan bersaing. Perusahaan harus mampu mengelolanya agar dapat menciptakan keunggulan bersaing dan mendapatkan keuntungan. Kunci sukses bagi suatu industri bisnis yang berada pada lingkungan yang mengalami perubahan secara terus menerus dalam lingkungan persaingan dapat mencapai keunggulan bersaing yang efektif (Adiputra dan Mandala, 2017).

PT. Solo Murni (Kiky Creative Product) adalah perusahaan percetakan yang berspesialisasi dalam percetakan yang menghasilkan berbagai macam produk dengan tingkat pergantian tertentu yang didistribusikan hampir merata dan relatif rendah. Namun seiring dengan permintaan tenaga khususnya di bagian produksi yang semakin berkurang serta banyaknya peluang kerja di perusahaan lain, memberikan dampak berkurangnya tenaga kerja di perusahaan tersebut. Berdasarkan pengamatan awal saat melakukan observasi di lokasi yang akan diteliti, didapatkan keterangan dari bagian HRD PT. Solo Murni tentang fluktuasi bulanan keluar masuknya karyawan yang disebabkan berbagai alasan dengan kisaran 7 hingga 85 karyawan dalam satu tahun terakhir.

Tingkat turnover karyawan berdasarkan perhitungan sementara dari data yang didapatkan saat pengamatan awal tersebut berkisar antara 14,24\% dengan jumlah perbandingan 334 karyawan keluar dan 279 karyawan masuk selama 12 bulan sejak Januari 2019 hingga Desember 2019. Adapun jumlah karyawan tetap sebanyak 1422 karyawan dan kontrak sebanyak 988 karyawan. Berdasarkan uraian tersebut, maka peneliti berpendapat bahwa layak melakukan penelitian di PT. Solo Murni dengan mengambil judul "Turnover Intention Ditinjau Dari Komitmen, Kepuasan Kerja dan Keunggulan Bersaing (Studi Kasus Pada Karyawan PT. Solo Murni)".

\section{METODE PENELITIAN}

Jenis penelitian adalah penelitian kuantitatif dengan menggunakan metode survei dan dokumentasi dengan tujuan untuk memperoleh keterangan dan fakta-fakta secara deskriptif kuantitatif. Penelitian ini dilakukan di PT. Solo Murni yang beralamat di Jl. Solo-Semarang KM 14, Bangak, Banyudono, Boyolali. Karena PT. Solo Murni adalah perusahaan yang relatif besar dengan karyawan sebanyak 2410 orang yang terdiri dari 1422 karyawan tetap dan 988 karyawan kontrak berdasarkan laporan HRD per 25 Januari 2020. Sampel adalah bagian dari jumlah dan karakteristik populasi (Sugiyono, 2013: 149). Pengambilan sampel dengan teknik Cluster Sampling dengan rumus slovin sebagai berikut: 
$n=\frac{N}{1+N e^{2}}$

Keterangan:

n : Jumlah sampel

$\mathrm{N}$ : Jumlah populasi

e : Presisi (ditetapkan 10\%)

$\mathrm{n}=\frac{2410}{1+2410(0.1)^{2}}=96,0159$

Jadi dari hasil perhitungan tersebut jumlah sampel yang diteliti yaitu sebesar 96,0159 responden dibulatkan ke atas jadi sebesar 97 responden, terdiri dari karyawan tetap sebanyak 57 dan 40 karaywan kontrak.

\section{HASIL DAN PEMBAHASAN}

a. Uji Normalitas

Tabel 1

Hasil Uji Normalitas

One-Sample Kolmogorov-Smirnov

Test

\begin{tabular}{|c|c|c|}
\hline & & $\begin{array}{c}\text { Unstandar } \\
\text { dized } \\
\text { Residual }\end{array}$ \\
\hline $\mathrm{N}$ & & 97 \\
\hline Normal & Mean & .0000000 \\
\hline Parameters ${ }^{\mathrm{a}}$ & Std. & 2.600497 \\
\hline & Deviation & 46 \\
\hline Most & Absolute & .070 \\
\hline Extreme & Positive & .070 \\
\hline Differences & Negative & -.045 \\
\hline Kolmogorov & -Smirnov Z & .685 \\
\hline Asymp. Sig. & (2-tailed) & .736 \\
\hline
\end{tabular}

Pada tabel tersebut terlihat bahwa tanda $\mathrm{z}$ adalah 0,685 dengan nilai $\mathrm{p} 0,736$ pada $\mathrm{p}>0,05$, dapat disimpulkan bahwa data terdistribusi normal dan model regresi sesuai dengan asumsi normalitas.

\section{b. Hasil Uji Multikolinearitas}


Tabel 2

Hasil Uji Multikolinearitas

Coefficients $^{\mathrm{a}}$

\begin{tabular}{llll}
\hline \hline Model & \multicolumn{2}{c}{ Collinearity } \\
& & \multicolumn{2}{c}{ Statistics } \\
\cline { 3 - 4 } & \multicolumn{2}{l}{ Tolerance } & VIF \\
\hline \multicolumn{4}{c}{ ) } \\
\cline { 2 - 3 } & $\mathrm{X} 1$ & .509 & 1.965 \\
& $\mathrm{X} 2$ & .565 & 1.771 \\
& $\mathrm{X} 3$ & .429 & 2.332 \\
\hline \hline
\end{tabular}

a. Dependent Variable: Y

Tabel tersebut menunjukkan komit-men karyawan (X1) memiliki nilai toleransi 0,509 lebih besar dari batas toleransi 0,10 dan nilai VIF 1965 yang kurang dari batas VIF 10 maka dipastikan bahwa variabel keterlibatan karyawan (X1) dalam studi multikolinearitas ini tidak terjadi. Ini juga terjadi dengan variabel dependen lainnya, terutama kepuasan kerja (X2) dan keunggulan kompetitif (X3), yang memiliki nilai toleransi di atas batas toleransi dan nilai VIF di bawah batas VIF, disimpulkan bahwa tidak terjadi multikolinier regresi.

\section{c. Hasil Uji Heteroskedastisitas}

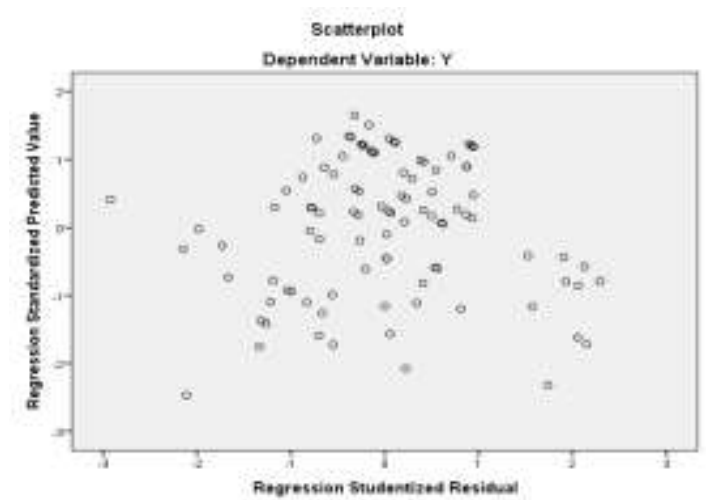

Gambar 1. Skema Grafik Scatterplot

Grafik Scatterplot di atas menjelaskan bahwa sebaran tersebut tidak membentuk pola tertentu (menyebar) maka dapat disimpulkan bahwa model regresi penelitian ini tidak terjadi heteroske-dastisitas.

\section{PENGUJIAN HIPOTESIS}

\section{a. Uji Analisis Regresi Linier Berganda}

Tabel 3 


\begin{tabular}{llrr}
\multicolumn{2}{c}{ Hasil Analisis Regresi Linier Berganda } \\
\hline \hline Model & \multicolumn{2}{c}{$\begin{array}{c}\text { Unstandardized } \\
\text { Coefficients }\end{array}$} \\
\cline { 2 - 4 } & \multicolumn{1}{c}{ B } & Std. Error \\
\hline & (Constant) & 2.440 & 1.677 \\
1 & X1 & .287 & .106 \\
& X2 & .367 & .104 \\
& X3 & .238 & .105 \\
\hline \hline
\end{tabular}

Berdasarkan regresi tersebut dihasilkan persamaan:

$\mathrm{Y}=2,440+0,287 \mathrm{X} 1+0,367 \mathrm{X} 2+0,238 \mathrm{X} 3+\mathrm{e}$

\section{b. Koefisien Determinasi}

Tabel 4

Hasil Uji Koefisien Determinasi

Model Summary ${ }^{b}$

\begin{tabular}{|c|c|c|c|c|}
\hline $\begin{array}{l}\text { Mode } \\
1\end{array}$ & $\mathrm{R}$ & $\begin{array}{c}\mathrm{R} \\
\text { Square }\end{array}$ & $\begin{array}{l}\text { Adjusted } \\
\text { R Square }\end{array}$ & $\begin{array}{l}\text { Std. } \\
\text { Error of } \\
\text { the } \\
\text { Estimat } \\
\text { e }\end{array}$ \\
\hline 1 & $.732^{a}$ & .535 & .520 & 2.642 \\
\hline
\end{tabular}

a. Predictors: (Constant), X3, X2, X1

b. Dependent Variable: Y

Tabel tersebut menunjukkan nilai $\mathrm{R}^{2}$ diperoleh dalam analisis regresi berganda diperoleh angka koefisien determinasi dengan nilai Adjusted $\mathrm{R}^{2}$ sebesar 0,520. Hal ini berarti bahwa presentase sumbangan pengaruh komitmen karyawan, kepuasan kerja, dan keunggulan bersaing terhadap turnover intention sebesar 52\%. Sedangkan sisanya $48 \%$ dijelaskan oleh faktor-faktor lain diluar model yang diteliti. Seperti gaji, motivasi, reward, dan lain sebagainya.

\section{c. Uji F}

Tabel 5

Hasil Uji F

ANOVA ${ }^{a}$ 


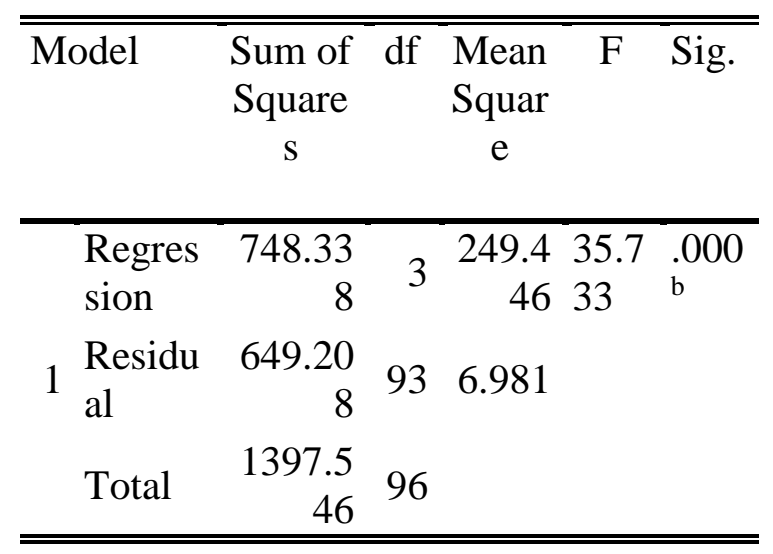

Tabel teserbut menunjukkan $\mathrm{F}_{\text {hitung }}$ sebesar 35,733 sedangkan nilai $\mathrm{F}_{\text {tabel }}$ didapatkan dari rumus Ftabel $=0,05(\mathrm{k} ; \mathrm{n}-\mathrm{k}-1)$, sehingga $(3 ; 97-3-1)$ pada taraf signifikan $\alpha=5 \%$ didapatkan $(3 ; 93)$ sebesar 2,70. Jadi, $F_{\text {hitung }}$ lebih besar dari $F_{\text {tabel }}(35,733>2,70)$. Nilai signifikan sebesar 0,000 menunjukkan nilai yang lebih rendah dari nilai signifikansi yang telah ditentukan sebelumnya yaitu $0,05(0,000<0,05)$. Sehingga $\mathrm{H}_{0}$ ditolak, maka dapat disimpulkan bahwa variabel komitmen $\left(\mathrm{X}_{1}\right)$, kepuasan kerja $\left(\mathrm{X}_{2}\right)$ dan keunggulan bersaing $\left(\mathrm{X}_{3}\right)$ secara bersama-sama berpengaruh positif dan signifikan terhadap turnover intention karyawan (Y).

\section{d. Uji t}

Tabel 6

Hasil Uji t

\begin{tabular}{llcc}
\hline \hline Model & $\mathrm{t}$ & sig. \\
\hline \multirow{2}{*}{$\begin{array}{l}\text { (Constant) } \\
\text { 1 }\end{array}$ Komitmen (X1) } & 1.455 & .149 \\
& Kepuasan (X2) & 3.699 & .008 \\
& Keunggulan & 2.277 & .001 \\
& bersaing (X3) & & \\
\hline \hline
\end{tabular}

a. Dependent Variable: Y

Tabel tersebut menunjukan komitmen karyawan memiliki $t_{\text {hitung }} 2,699$. Sedangkan $t_{\text {tabel }}$ didapatkan dari rumus $t_{\text {tabel }}=(\alpha / 2, n-k)$, sehingga $(0,05 / 2 ; 97-3)$ atau $(0,025 ; 94)$ pada taraf signifikan $\alpha=5 \%$ diketahui $\mathrm{t}_{\text {tabel }}=1,98$. Dengan demikian, $\mathrm{t}_{\text {hitung }}>\mathrm{t}_{\text {tabel }} 1,98$, berarti Ho ditolak.

Kepuasan karyawan memiliki nilai $t_{\text {hitung }} 3$,535. Sedangkan $t_{\text {tabel }}$ didapatkan dari rumus $\mathrm{t}_{\text {tabel }}=(\alpha / 2, \mathrm{n}-\mathrm{k})$, sehingga $(0,05 / 2 ; 97-3)$ atau $(0,025 ; 94)$ pada taraf signifikan $\alpha=5 \%$ diketahui $\mathrm{t}_{\text {tabel }}=1,98$. Dengan demikian, $\mathrm{t}_{\text {hitung }}>\mathrm{t}_{\mathrm{tabel}} 1,98$, berarti Ho ditolak. Pada nilai signifikan memiliki nilai $0,001<0,05$.

Keunggulan bersaing memiliki nilai $t_{\text {hitung }} 2,277$. Sedangkan $t_{\text {tabel }}$ didapatkan dari rumus $t_{\text {tabel }}=(\alpha / 2, n-k)$, sehingga $(0,05 / 2 ; 97-3)$ atau $(0,025 ; 94)$ pada taraf signifikan $\alpha=5 \%$ diketahui $\mathrm{t}_{\text {tabel }}=1,98$. Dengan demikian, $\mathrm{t}_{\text {hitung }}>\mathrm{t}_{\text {tabel }} 1,98$, berarti Ho ditolak. Pada nilai signifikan memiliki nilai $0,025<0,05$.

\section{PEMBAHASAN}




\section{1) Pengaruh Komitmen, Kepuasan Karyawan, dan Keunggulan Besaing Terhadap} Turnover Intention Karyawan di PT Solo Murni.

Berdasarkan hasil perhitungan SPSS diperoleh $F_{\text {hitung }}>F_{\text {tabel }}(35,733>2,70)$ dan signifikansi $0,000<0,05$. Artinya komitmen, kepuasan kerja, dan keunggulan bersaing memiliki pengaruh secara simultan dan signifikan terhadap turnover intention. Semakin tinggi komitmen, kepuasan kerja, dan keunggulan bersaing, maka pada turnover intention akan mengalami peningkatan secara nyata.

\section{2) Pengaruh Komitmen Karyawan Terhadap Turnover Intention Karyawan di PT} Solo Murni.

Berdasarkan hasil perhitungan SPSS diperoleh $t_{\text {hitung }}>t_{\text {tabel }}(2,699>1,985)$ dengan koefisien regresi bernilai positif sebesar 0,287. Artinya komitmen berpengaruh positif dan signifikan terhadap turnover intention. Apabila komitmen karyawan tinggi, maka turnover intention akan semakin meningkat.

3) Pengaruh Kepuasan Kerja Karyawan Terhadap Turnover Intention di PT Solo Murni.

Berdasarkan hasil perhitungan SPSS diperoleh $t_{\text {hitung }}>t_{\text {tabel }}(3,535>1,985)$ dengan koefisien regresi bernilai positif sebesar 0,367. Artinya kepuasan kerja berpengaruh positif dan signifikan terhadap turnover intention. Apabila kepuasan kerja meningkat, maka akan meningkatkan turnover intention.

\section{4) Pengaruh Keunggulan Bersaing Terhadap Turnover Intention di PT Solo Murni.}

Berdasarkan hasil perhitungan SPSS diperoleh $t_{\text {hitung }}>t_{t a b e l}(2,277>1,985)$ dengan koefisien regresi bernilai positif sebesar 0,238. Artinya keunggulan bersaing berpengaruh positif dan signifikan terhadap turnover intention. Apabila keunggulan bersaing meningkat, maka akan meningkatkan turnover intention.

\section{KESIMPULAN}

Berdasarkan analisis data disimpulkan:

1) Hasil uji $F$ menunjukkan ada pengaruh simultan dan signifikan komitmen, kepuasan kerja, dan keunggulan bersaing terhadap turnover intention karyawan pada PT. Solo Murni (Kiky) di Kabupaten Boyolali.

2) Hasil uji t menunjukkan:

a. Komitmen berpengaruh positif dan signifikan terhadap turnover intention karyawan di perusahaan PT. Solo Murni (Kiky) di Kabupaten Boyolali.

b. Kepuasan kerja berpengaruh positif dan signifikan terhadap turnover intention karyawan di perusahaan PT. Solo Murni (Kiky) di Kabupaten Boyolali.

c. Keunggulan bersaing berpengaruh positif dan signifikan terhadap turnover intention karyawan di perusahaan PT. Solo Murni (Kiky) di Kabupaten Boyolali.

3) Hasil uji regresi menunjukkan persamaan estimasi sebagai berikut $Y=2,440+0,287 \mathrm{X} 1$ $+0,367 \mathrm{X} 2+0,238 \mathrm{X} 3+\mathrm{e}$. Artinya komitmen, kepuasan kerja, dan keunggulan bersaing bernilai positif terhadap turnover intention, masing-masing variabel, komitmen peningkatan sebesar 0,287, kepuasan kerja sebesar 0,367, dan keunggulan bersaing sebesar 0,238.

4) Koefisien determinasi sebesar Adjusted $\mathrm{R}^{2}$ 0,520 menunjukkan besarnya presentase sumbangan pengaruh komitmen, kepuasan kerja, dan keunggulan bersaing terhadap turnover intention sebesar 52\%. Sedangkan sisanya $48 \%$ dijelaskan oleh faktor-faktor lain diluar model yang diteliti. Seperti gaji, motivasi, reward, dan lain sebagainya. 


\section{DAFTAR PUSTAKA}

Adiputra, I. P. P., \& Mandala, K. (2017). Pengaruh Kompetensi dan Kapabilitas Terhadap Keunggulan Kompetitif dan Kinerja Perusahaan. E-Jurnal Manajemen Unud, Vol. 6, No. 11.

Hafni, L., \& Lyana, L. (2016). Pengaruh Seleksi, Kepuasan Kerja dan Komitmen Organisasi Terhadap Turnover Intention Karyawan pada PT. Surya Perdana Agung Pekanbaru. Jurnal KURS, Vol. 1, No. 1.

Melky, Y. (2015). Hubungan Kepuasan Kerja dan Komitmen Organisasi Terhadap Intensi Pindah Kerja (Turnover Intention) Karyawan PT. Rejeki Abadi Sakti Samarinda. eJournal Psikologi, Vol. 3, No. 3.

Paripurna, I. G. D., Supartha, I. W. G., \& Subudi, M. (2017). Pengaruh Kepemimpinan dan Kepuasan Kerja Terhadap Turnover Intention Serta Dampaknya Terhadap Kinerja Karyawan pada PT Agung Automall Kuta. E- Jurnal Ekonomi dan Bisnis Universitas Udayana, Vol.6, No. 6.

Soekiyono. (2017). Pengaruh Kepuasan Kerja dan Motivasi Terhadap Turnover Intentions Dengan Komitmen Sebagai Variabel Mediasi (Survey Karyawan Pada Sektor Retail “Alfa Mart”). Jurnal Ilmiah FE-UMM, Vol. 11, No. 2.

Sugiyono. (2013). Metode Penelitian Kuantitatif, Kualitatif dan R\&D. Cetakan Ke-19. Bandung: Alfabeta. 